\title{
Identificação e Descrição de Relações Comportamentais na Economia Solidária
}

Identification and description of behavior relations in solidary economy

\section{Ana Lucia Cortegoso}

Universidade Federal de São Carlos

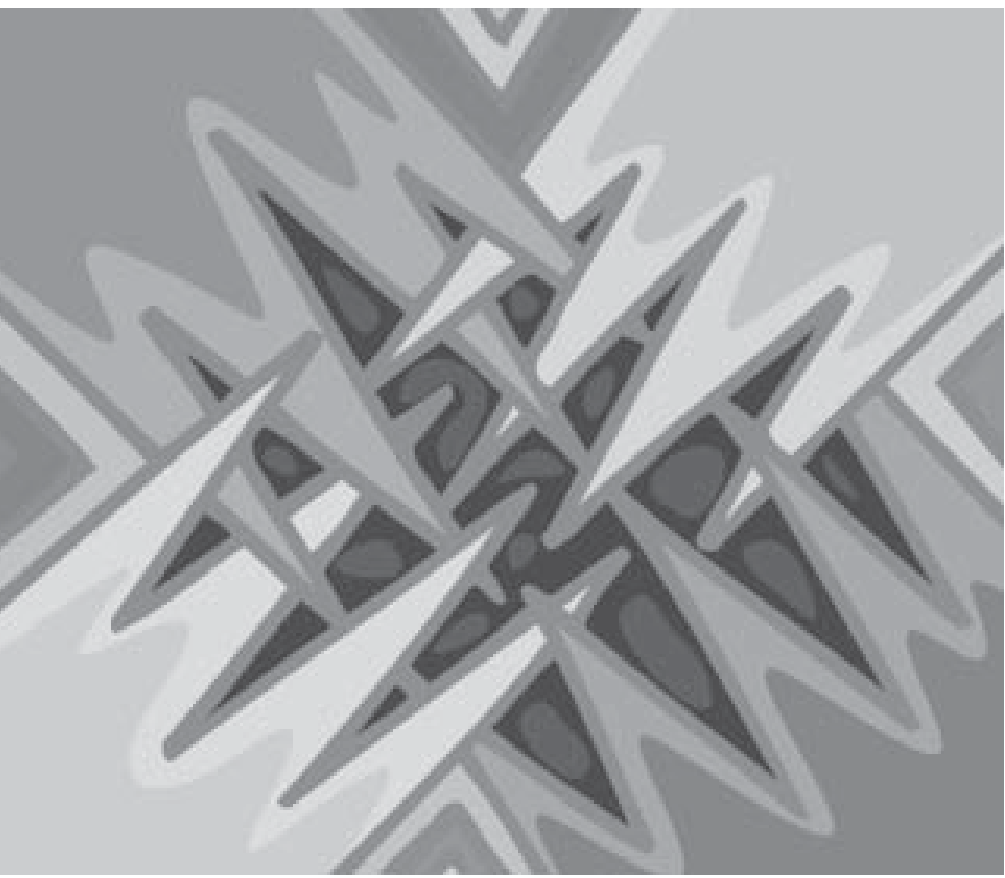




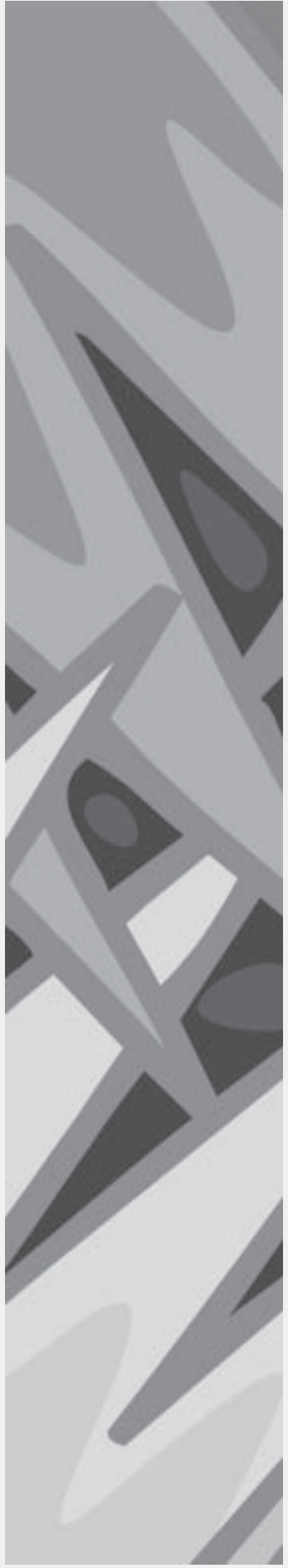

Resumo: Que comportamentos, nas relações organismo-ambiente, fazem parte da economia solidária como organização para o trabalho e repercussão na sociedade? A partir de observação e registro de informações em situações de trabalho em uma incubadora universitária de empreendimentos solidários, consulta a documentos de atividades realizadas e literatura e entrevistas sobre aspectos da atuação de diferentes tipos de atores nesse campo de atividade humana, foi possível identificar e descrever comportamentos organizacionais e individuais. Tais comportamentos são considerados relevantes para práticas culturais cooperativas, distribuição eqüitativa dos benefícios do trabalho e relação menos predatória do homem com seu ambiente, inclusive social, em termos de relações ambiente-organismo. O produto deste estudo, como sistematização de atividades de uma agência universitária destinada a incubar empreendimentos solidários, representa contribuição para a compreensão do papel de diferentes atores sociais no complexo fenômeno social que é a economia solidária, a partir do conceito de comportamento como proposto pela análise do comportamento.

Palavras-chave: comportamentos em economia solidária, comportamentos organizacionais, práticas culturais no trabalho, economia solidária.

Abstract: Which behaviors, in the ambient-organisms relations, are concerned with solidary economy as a form of organization for work that reflects on society? Data accessed by interviews, from documents and permanent register of information in situations of collective work about aspects of performance from actors in that human activity field allowed identifying and describing organizational and individual behaviors. These were considered relevant to cooperative cultural practices, equitable distribution of the benefits of work and a less predatory relation of the human being with his environment, including the social one. The product of this study, as a systematization of activities in an agency that incubates solidary groups, represents a contribution for better understanding about the role of different social actors in the complex social phenomena that is solidary economy, based on the use of concepts as behavior according to the behavior analysis view.

Key words: behaviors in solidary economy, organizational behavior, cultural practices in work, solidary economy. 
Acesso ao conhecimento da Psicologia como condição para mudar as relações do homem com seu meio

Um dos grandes desafios atuais da ciência, para que esta possa cumprir seu papel social, é transformar conhecimento em comportamentos humanos significativos, para que pessoas e instituições lidem com seu ambiente de forma a promover uma sociedade mais justa e equilibrada, como parte do próprio processo de produzir conhecimento (Botomé, 1996).

Overstreet (1978), há quase trinta anos, afirmava que o conhecimento característico do século era o psicológico, e o avanço da Psicologia, como área do conhecimento, foi certamente imenso nesse período que, segundo o autor, trouxe uma nova atitude em relação à natureza e à experiência humana. Sob qualquer ponto de vista (quantidade e qualidade de publicações, diversidade de temas e problemas estudados, número de instituições formadoras de profissionais de nível superior, bacharéis, licenciados e psicólogos, programas de pós-graduação, frentes de atuação profissional e de demandas por atuação), é possível apontar progressos importantes na contribuição oferecida pela Psicologia para a compreensão dos fenômenos psicológicos e para o exercício profissional nesse campo. O desafio, porém, continua existindo, e não é de pequena proporção, considerando os problemas que ainda devem ser enfrentados em produção de conhecimento e tecnologia em Psicologia, mas, principalmente, pelo baixo grau de acesso da humanidade ao conhecimento já disponível sobre as questões que constituem o objeto dessa área de conhecimento.

A quantidade e a diversidade de conhecimento já existente, ainda que em graus diferentes de desenvolvimento e consolidação, no âmbito da Psicologia, é muito grande, e torná-lo acessível é uma tarefa para muitos. A sistematização e o exame de trabalhos de psicólogos e pesquisadores em Psicologia, particularmente como membros de equipes multiprofissionais e de grupos de pesquisa multidisciplinares, no campo da economia solidária, constituem uma possibilidade, dentre as várias que buscam garantir a conclusão do processo de produção de conhecimento, ou seja, a produção de mudanças de comportamentos compatíveis com esse conhecimento.

\section{Economia solidária, práticas culturais e metacontingências}

De acordo com documento da Secretaria Nacional de Economia Solidária (SENAES, 2004), esse movimento corresponde a um conjunto de atividades econômicas de produção, distribuição, consumo, poupança e crédito, organizadas sob a forma de autogestão, isto é, pela propriedade coletiva dos meios de produção de bens ou prestação de serviços, pela participação democrática nas decisões dos membros da organização ou empreendimento e pela distribuição eqüitativa dos resultados do trabalho. Empreendimentos solidários são, assim, organizações de trabalho cujas características básicas são a propriedade coletiva ou associada ao capital e o direito à liberdade individual (Singer, 2002), nos quais os trabalhadores são, simultaneamente, donos de seu próprio negócio, sendo as cooperativas as formas mais conhecidas desse tipo de empreendimento (Singer, 2000). Sob a orientação de um conjunto de princípios (adesão livre e voluntária, participação econômica eqüitativa dos sócios, controle democrático, pelos sócios, na definição das políticas do empreendimento e nos processos de tomada de decisão, educação, treinamento e formação para os sócios, intercooperação e preocupação com a comunidade), esses empreendimentos têm surgido, no Brasil, a partir da década de 1990, como forma alternativa de geração de trabalho e renda para segmentos excluídos da população. São, 
também, e talvez fundamentalmente, organizações dentro das quais são esperadas relações humanas muito diversas daquelas promovidas por uma organização social essencialmente competitiva: relações de igualdade, colaboração e preocupação com o bem-estar do ser humano como valor essencial.

Ainda que seja a cooperativa a forma mais conhecida de empreendimento solidário, nem todas as cooperativas fazem parte ou são consideradas de economia solidária. A trajetória do cooperativismo no Brasil levou ao surgimento de dois tipos de iniciativas econômicas, além daquelas indicadas como atores principais na economia solidária: o primeiro deles, relativo a empreendimentos que, inseridos no que pode ser chamado de grande cooperativismo, na prática, pouco se diferenciam das empresas tradicionais em termos da hierarquização das relações no trabalho; o segundo, a cooperativas fraudulentas, nas quais os trabalhadores apenas aparentemente são donos dos meios de produção e do poder de decisão, e são submetidos a uma condição de precariedade trabalhista, já que, como donos legais desses empreendimentos, não têm acesso garantido aos direitos trabalhistas. Por essas razões, da economia solidária, fazem parte cooperativas denominadas populares, como indicação não só da população que as compõe mas também dos compromissos que assumem seus membros com princípios consagrados pelo movimento, podendo a autogestão ser considerada o principal deles.

De acordo com os dados apresentados no Atlas da Economia Solidária no Brasil - 2005 (BRASIL, 2006), a partir de trabalho de mapeamento da economia solidária que alcançou 2274 Municípios brasileiros (41\% do total), 14954 empreendimentos econômicos solidários foram visitados, e sobre eles foram obtidas informações diversas. Além desses empreendimentos econômicos solidários (organizações de finanças solidárias, empresas autogestionárias, cooperativismo popular, redes de empreendimentos, associações, clubes de troca), fazem parte da economia solidária, no Brasil, diferentes atores, como: instâncias governamentais (em nível federal, estadual e municipal), entidades de apoio e fomento (universidades, ongs, organizações de natureza religiosa, movimento sindical), ligas e uniões, instâncias de organização política do movimento, como os fóruns de economia solidária (municipais, estaduais e brasileiro), redes (de gestores públicos, por exemplo), e outros.

A implementação da economia solidária, com as características indicadas, pode ser entendida como resultado, a longo prazo, da atuação de diferentes atores sociais, pessoas e instituições de diferentes tipos. O conceito de metacontingência (Glenn, 1991, entre outros), como unidade de análise que descreve relações funcionais entre práticas culturais resultantes de contingências comportamentais entrelaçadas e de seus produtos agregados, permite descrever apropriadamente o fenômeno da economia solidária. Este resulta dos esforços de um número considerável de iniciativas nesse campo, com a perspectiva de mudança cultural na direção de relações econômicas mais igualitárias e humanas de melhor qualidade, do ponto de vista do bemestar dos indivíduos, do que as predominantes, em que o ser humano é, em geral, um meio para o acúmulo de capital.

A preocupação com a produção de um outro tipo de cultura para o homem, de maior igualdade social e confiança entre os seres humanos, não é nova na análise do comportamento, e está presente na obra de F. S. Skinner, fundador dessa abordagem, desde muito cedo, conforme demonstram trabalhos como o de Andery (1990). Para Skinner, o conhecimento produzido no âmbito da análise do comportamento constituía ferramenta essencial para a construção dessa nova
A preocupação com a produção de um outro tipo de cultura para o homem, de maior igualdade social e confiança entre os seres humanos, não é nova na análise do comportamento, e está presente na obra deF.S. Skinner, fundador dessa abordagem desde muito cedo, conforme demonstram trabalhos como o de Andery (1990) 
sociedade, que o autor chegou a ilustrar em uma novela, Walden Two (Skinner, 1977), quando esse conhecimento era ainda muito menor do que o que hoje se encontra disponível. Há bastante tempo, o pesquisador lançou os elementos que permitiriam, mais recentemente, o desenvolvimento mais pleno de condições para o estudo de fenômenos sociais complexos e para uma efetiva interferência em relação a esses fenômenos. A perspectiva de compreensão da economia solidária como resultado de um conjunto de práticas culturais entrelaçadas, cujas relações podem ser descritas por meio de metacontingências, requer e facilita melhor examinar o papel de cada um dos atores relevantes para a produção desse resultado. Mais do que uma opção ideológica relacionada à cooperação entre esses atores, a economia solidária é um fenômeno que só poderá resultar da ação de muitos atores, pessoas, grupos e organizações, articuladas na mesma direção, ainda que as práticas de cada um deles apresentem especificidades e sejam mantidas por conseqüências imediatas específicas. Identificar e descrever as práticas específicas dos principais atores que contribuem para o resultado final desse fenômeno constitui uma contribuição relevante para a implementação da economia solidária como alternativa social e econômica.

\section{Noção de comportamento como ferramenta para descrever e examinar práticas no âmbito da economia solidária}

A definição de comportamento operante apresentada por Botomé (1981), como resultado da sistematização do conhecimento produzido no contexto da análise do comportamento sobre o comportamento humano, pode constituir referência para o exame de fenômenos aqui destacados como partes significativas das relações das quais, espera-se, resulte a economia solidária, com a qual se comprometem diferentes atores sociais. De acordo com esse autor, o comportamento humano, de natureza operante, que representa a unidade mínima de interesse para estudo e intervenção, é a relação entre um determinado tipo de ação, ou classe de respostas, e os aspectos relevantes do ambiente. Em outras palavras, os aspectos ambientais são funcionalmente relacionados com essa classe de respostas, antecedendo-a (classes de estímulos antecedentes), e os aspectos, também funcionalmente relacionados a ela, que resultam (ou devem resultar) desse tipo de ação (classes de estímulos subseqüentes ou conseqüentes, sendo as expressões subseqüentes $\mathrm{e}$ conseqüentes utilizadas como equivalentes, neste trabalho).

Essa noção de comportamento, embora aparentemente simples, constitui uma contribuição de valor inestimável para a compreensão do agir humano e uma ferramenta poderosa para lidar com situações em que esse agir esteja presente ou pareça desejável. Compreender o comportamento humano como uma relação implica reconhecêlo como fenômeno essencialmente dinâmico, de múltiplas direções, com o homem interferindo no ambiente tanto quanto esse ambiente interfere no agir humano, um conceito que inclui, como parte mesmo do agir humano, decorrências das ações do homem em relação a esse ambiente, ou seja, a dimensão ética da relação. Tal mudança exige, inclusive, alterações na linguagem utilizada para fazer referência aos fenômenos que envolvam comportamentos humanos, cuja presença é, muitas vezes, obscurecida pelo uso de substantivos.

A contribuição dada pelo conceito de comportamento, ao afirmar a importância de compreender o agir humano não considerando apenas o que o organismo faz, mas o contexto em que esse fazer se insere, e a especificar aspectos desse contexto que são fundamentais 
como parte dessa relação, traz um referencial para o exame da atuação de outros atores sociais, ainda que não sejam eles pessoas. De acordo com Glenn e Mallot (2004), "organizações consistem da interação dinâmica entre o comportamento de seres humanos e seus produtos", e a expressão "comportamento organizacional" refere-se, também, ao comportamento das organizações como entidades funcionais. Nessas condições, descrições comportamentais, entendidas como especificações de relações entre aspectos do ambiente e da atuação dos organismos, daquilo que é ou pode ser esperado de organizações que desempenham importante papel em relação à implementação da economia solidária, podem trazer contribuições relevantes para a compreensão e para o exercício desses papéis. Verificar a fecundidade do uso desse referencial ao estabelecer objetivos para alguns dos atuais atores da economia solidária constitui o objetivo deste estudo.

No conjunto de atuações que contribuem para a constituição do resultado de interesse social, ao menos no contexto brasileiro atual, denominado economia solidária, cabe à instituição Universidade, como agência de fomento desse campo, desenvolver, de acordo com Cortegoso e Shimbo (2005), especificamente, a "produção de conhecimento e tecnologia para o desenvolvimento da economia solidária, tanto em relação ao estudo de cadeias produtivas quanto no que se refere ao cooperativismo e à autogestão administrativa dos empreendimentos, assim como garantia de acesso, por parte dos empreendimentos, a tais conhecimentos e tecnologias." Uma das formas por meio das quais universidades brasileiras têm buscado cumprir esse papel é pela criação das denominadas incubadoras universitárias de cooperativas (ou, mais amplamente, empreendimentos solidários), a partir de meados da década de 1990. Com ações destinadas à incubação de cooperativas populares, tendo como público-alvo os desempregados historicamente excluídos ou aqueles expulsos do mercado formal de trabalho em virtude dos processos tecnológicos, da privatização de empresas estatais ou de terceirização dos serviços, com a presença de populações mais empobrecidas e pessoas com deficiências, essas agências surgiram e se organizaram buscando favorecer a criação de novas oportunidades de trabalho e renda, por meio de empreendimentos coletivos, solidários e autogestionários. Atualmente, apenas em uma das redes universitárias existentes (Rede de Incubadoras Tecnológicas de Cooperativas Populares - ITCPs), o número de incubadoras desse tipo se aproxima de trinta.

De acordo com Cortegoso et al. (2005a), "um dos desafios enfrentados por esses núcleos de ensino, pesquisa e extensão que se dedicam à economia solidária é desenvolver métodos de incubação capazes de viabilizar não apenas a existência de coletivos organizados para o trabalho mas também seu funcionamento como células efetivamente autogestionárias e comprometidas com os princípios orientadores da economia solidária e a inserção dessas células em complexas redes de relações que envolvem outros empreendimentos solidários, outros atores sociais da economia solidária, e mesmo no mercado capitalista, pouco amistoso a essa forma de organização do trabalho e gestão." Neste trabalho, são apresentadas, como resultado de um processo de sistematização de conhecimento produzido sobre a atuação de diferentes atores da economia solidária, a partir de atividades de ensino e intervenção profissional desenvolvidas em uma incubadora universitária de empreendimentos solidários, formulações de classes de comportamentos que vêm se evidenciando como relevantes para a construção da economia solidária, tal como definida anteriormente neste texto. Tal sistematização representa tanto referencial para "um dos desafios enfrentados por esses núcleos de ensino, pesquisa e extensão que se dedicam à economia solidária é desenvolver métodos de incubação capazes de viabilizar não apenas a existência de coletivos organizados para o trabalho mas também seu funcionamento como células efetivamente autogestionárias e comprometidas com os princípios orientadores da economia solidária e a inserção dessas células em complexas redes de relações que envolvem outros empreendimentos solidários, outros atores sociais da economia solidária, e mesmo no mercado capitalista, pouco amistoso a essa forma de organização do trabalho e gestão."

Cortegoso 
produção de conhecimento novo, a partir de investigações sobre propriedades das classes de comportamentos e sua relação com os resultados finais pretendidos, quanto condição para intervenção no processo de desenvolvimento dessa prática cultural, em relação à qual parece existir interesse social dos diferentes envolvidos.

\section{Aspectos metodológicos para identificação e descrição de comportamentos em economia solidária}

Fontes de informações, procedimentos e instrumentos utilizados para coleta e análise de dados.

Em relação ao que é esperado de uma incubadora universitária de cooperativas populares (classes de comportamentos da incubadora), constituíram fontes de informação: documentos norteadores da economia solidária, elaborados no período da coleta de dados pela Secretaria Nacional de Economia Solidária e pelo Fórum Brasileiro de Economia Solidária; documentos descritivos de atividades previstas e desenvolvidas nos processos de incubação de grupos atendidos pela equipe da incubadora, produzidos no decorrer desse processo por seus responsáveis (relatórios de projetos de incubação, relatórios de estágio de alunos de graduação que realizaram intervenções junto a grupos incubados, atas de reuniões da equipe em situações, rotineiras ou específicas, para monitoramento e avaliação de projetos de incubação implementados, anotações em cadernos de campo sobre atividades realizadas, problemas encontrados, resultados alcançados nesses processos e possibilidades de atuação alternativa ou complementar); observação direta de situações de trabalho da equipe da incubadora, como reuniões internas (da incubadora, de equipes responsáveis por projetos de incubação específica) e de interação de membros da equipe com os grupos assessorados, com registro de comportamentos apresentados por esses membros e suas decorrências, efetivas ou potenciais, em termos de referenciais da economia solidária (autogestão, autonomia, etc), para o processo de incubação. Tais informações foram obtidas diretamente pela pesquisadora, também participante da equipe da incubadora, e por auxiliares de pesquisa, por um período de três anos. Todas as informações obtidas foram sistematizadas em termos de relações entre o que era esperado que a incubadora garantisse ao implementar o processo de incubação de empreendimentos solidários, as condições diante das quais era esperado o tipo de ação previsto e os resultados, produtos e efeitos dessa ação, como parte do processo de incubação de empreendimentos solidários. O produto dessa sistematização prossegue como objeto de estudo e discussão da equipe, que realiza, coletivamente, a adequação às descrições propostas, em função de avanços conceituais e novos dados advindos do processo de intervenção inerente à incubação. Tal processo se dá de forma articulada com a produção de conhecimento e ensino, com a participação de estudantes de graduação, técnicos de nível superior e alunos de pós-graduação na equipe. Em relação a comportamentos de membros de empreendimentos solidários, foram realizadas, por auxiliares de pesquisa treinados para essa finalidade, entrevistas com membros das equipes de trabalho de uma incubadora universitária de cooperativas populares com experiência no processo de incubação, a partir de uma pergunta geral (o que é importante que as pessoas que fazem parte de empreendimentos solidários sejam capazes de fazer?), e da solicitação de justificativas para as respostas apresentadas pelos entrevistados. A partir dos relatos verbais gravados em fita cassete e por meio de audição sucessiva das gravações, foram identificados e registrados, por esses auxiliares, relatos que se referiam a classes de comportamentos de indivíduos, em 
termos de classes de respostas, classes de estímulos antecedentes e classes de estímulos subseqüentes; essas informações foram registradas com a ajuda de um formulário que continha três colunas, uma para cada um dos componentes da relação comportamental. Foram identificadas, ainda, expressões indicativas dos objetivos a serem alcançados apenas coletivamente e a partir de comportamentos humanos diversificados e articulados, denominados classes de comportamentos de empreendimentos solidários como organismos. Versões preliminares dessas descrições foram sucessivamente revistas e adequadas, por auxiliares de pesquisa e pela pesquisadora, de modo a corrigir e completar tais descrições em função de dados coletados a partir da observação direta de situações de trabalho, internas ou junto a grupos atendidos, além de registros em cadernos de campo, feitas pela equipe da incubadora. As informações utilizadas para descrição da classe geral de comportamentos de consumidores, no âmbito da economia solidária, foram obtidas a partir do exame dos objetivos propostos por um grupo organizado de consumidores, produtores e consumidores e do processo de definição de objetivos (exame de documentos do grupo, tais como página web e atas de reuniões em que os objetivos foram definidos) e da observação direta desse processo de definição. Procedeu-se ao registro de relatos verbais dos participantes, no que se refere a condições diante das quais era esperado que ocorresse o padrão de consumo indicado como desejável, a partir de acordo coletivo do grupo e dos resultados, produtos e efeitos que precisariam ser garantidos ao lidar com as situações de consumo.

\section{Resultados e discussão}

Método de incubação ou incubar empreendimentos solidários?

A expressão método de incubação, freqüentemente utilizada para indicar o que cabe a (ou define) agências que dão apoio direto para a formação e a implementação de empreendimentos solidários, dificulta evidenciar que o fenômeno de interesse, considerando aquilo que é pretendido como produto social, refere-se ao que essas agências, por meio da atuação de cada um de seus membros, articuladamente, devem fazer. Isso envolve um processo comportamental complexo, descrito inicialmente por uma classe ampla e complexa de comportamentos organizacionais que, de forma articulada, ou pelo menos somada a todas as outras que compõem a especificidade social de cada um dos diferentes atores da economia solidária, pode influir na existência dessa forma de organização para o trabalho e nas suas características, denominada sinteticamente incubar empreendimentos solidários.

Essa não é, contudo, uma classe de comportamentos já suficientemente conhecida, ou com características idênticas em todos os contextos, mesmo considerando apenas os já conhecidos, em que a incubação de empreendimentos solidários se dá, ainda que se tratem de atores sociais com muito em comum, como são as incubadoras universitárias no Brasil. Considerando o estágio de conhecimento e de experiência acumulada nesse campo, na verdade, muito tem sido feito por tentativa e erro, a partir de referenciais gerais e, freqüentemente, genéricos, contando com recursos (humanos, materiais, conceituais, etc) diferenciados.

A construção de representações da prática existente, bem como daquilo que já é possível projetar como desejável em termos de ações individuais e organizacionais, para alcançar alguns produtos sobre os quais existe um certo consenso, como, por exemplo, características essenciais de empreendimentos de economia solidária tal como sintetizada pela Secretaria Nacional de Economia Solidária (SENAES, 2004) e pelo Fórum Brasileiro de Economia Solidária (FBES, 2005), em termos de classes de comportamentos, não significa criar modelos 
estáticos ou universais de atuação a serem seguidos, nem mesmo no âmbito da agência específica em que essa construção se dá. Tal representação constitui, ao contrário, ponto de partida para reflexão e permanente aprimoramento conceitual e instrumental dessa atuação - compreendendo que conceitos são ferramentas a serem adequadas à realidade para a qual são desenvolvidas e que devem mudar conforme muda essa realidade, em direções usualmente mais complexas.

Neste estudo, como resultado de sistematização de práticas que vêm sendo desenvolvidas em uma incubadora universitária a partir do trabalho com diferentes situações (populações, atividades produtivas, regiões, tipos de demandas, parcerias, referenciais teóricos, etc), com importante variabilidade comportamental por parte de seus membros ao responder às condições concretas em que atuam, e de reflexão sobre essas práticas à luz de propostas conceituais e políticas no campo da economia solidária, foram identificadas classes de comportamentos consideradas relevantes no processo de apoio à constituição e à implementação de empreendimentos solidários. Partiu-se do que foi considerado papel dessa agência no atendimento a esses empreendimentos, expresso como objetivo a ser alcançado, ou seja, por meio de uma classe de comportamentos. No quadro 1 , pode ser vista a definição dessa classe, tal como aprovada pela equipe da incubadora na época da coleta de dados.

Quadro 1. Definição de classe de comportamentos que constituem objetivo de uma incubadora universitária de cooperativas populares.

Diante de demandas compatíveis com critérios em vigor na agência para incubação de empreendimentos solidários, e de disponibilidade de recursos considerados necessários para isso, é esperado da incubadora que ela possa assessorar grupos para a formação de empreendimentos econômicos, por meio da oferta de subsídios e do acompanhamento do processo de tomada de decisão e implementação de atividades, com participação dos responsáveis pela incubação em todas as etapas do trabalho, incluindo avaliação de resultados, por meio de relações dialógicas. A assessoria tem, como objetivo, a promoção da existência e a consolidação de empreendimentos solidários de natureza popular, organizados para o trabalho coletivo e dotados de funcionamento autônomo, com capacidade para identificar suas próprias necessidades e providenciar para que estas sejam atendidas. Tais empreendimentos se acham inseridos no mercado e no contexto mais amplo da economia solidária e possuem características gradualmente mais compatíveis com os princípios de economia solidária.

A descrição da classe de comportamentos apresentada no quadro 1 evidencia não apenas aquilo que é esperado que a incubadora, atuante que é no processo de incubação de empreendimentos solidários, faça, do ponto de vista das respostas desse organismo, mas a relação desse agir (classe de respostas) com as condições (classes de estímulos antecedentes) diante das quais esse fazer ocorre ou deve ocorrer, ou que sinalizam que esse fazer seja desejável, necessário ou oportuno (demandas compatíveis com os critérios em vigor na agência para atendimento a grupos) e as que são necessárias para isso (recursos disponíveis). Ambas podem se alterar no tempo e de uma agência para outra - o que provavelmente ocorrerá, sendo o conceito de comportamento utilizado para representar esse fazer dinâmico como a própria realidade que pretende representar. Da descrição, fazem parte, ainda, indicações sobre os resultados, produtos e efeitos (classes de estímulos subseqüentes) que devem decorrer das respostas apresentadas pela incubadora. 
No quadro 2, extraído de Cortegoso et al. (2005b), podem ser vistas as classes de comportamentos mais específicas que foram identificadas, a partir dos dados obtidos, como desejáveis nesse processo de assessoramento a grupos em formação. Nesse quadro, as classes aparecem indicadas, de forma sintética, sem a explicitação de todas as propriedades relevantes dos estímulos antecedentes, das respostas e dos estímulos subseqüentes, e representam um mapeamento inicial de condutas da agência que devem ser consideradas ao lidar com o atendimento a qualquer grupo em relação ao qual surjam demandas que possam vir a ser atendidas pela agência, em função de sua missão e objetivos.

Quadro 2. Classes de comportamentos organizacionais indicados como relevantes no processo de incubação de empreendimentos solidários no contexto em que os dados foram coletados (extraído de Cortegoso et al., 2005b).

- processar demanda apresentada por diferentes atores sociais para a incubação de empreendimentos solidários;

- identificar população em potencial para a formação de empreendimento solidário;

- caracterizar, de forma o mais completa possível, diferentes envolvidos no processo de incubação;

- apresentar economia solidária como possibilidade de organização para geração de trabalho e renda, para população ou grupo em potencial, a fim de formar empreendimentos solidários; - apoiar a organização inicial do grupo para a tomada de decisão sobre formação (ou não) de empreendimento solidário;

- elaborar proposta de trabalho com participantes do grupo a ser incubado;

- promover a formação dos membros do grupo para a economia solidária, de forma contínua e permanente, de todas as maneiras possíveis;

- promover escolha de atividade econômica pelo grupo;

- promover condições para capacitação técnica em relação ao serviço ou produção ofertado pelo empreendimento, de forma permanente;

- promover formação contínua e permanente dos membros para a autogestão administrativa, em todas as oportunidades e de todas as maneiras possíveis;

- promover a elaboração de normas de funcionamento do empreendimento (estatuto e regimento interno) de maneira participativa;

- assessorar grupo para a legalização do empreendimento;

- assessorar grupo para a implantação do empreendimento;

- assessorar grupo para a implantação de sistema de monitoramento por meio de indicadores; - assessorar grupo para a implementação do empreendimento, de forma episódica e esporádica; - assessorar grupo para a participação em redes de cooperação e em iniciativas do movimento de economia solidária.

A construção de representações correspondentes ao que é - ou é entendido que deva ser - a atuação de qualquer organismo, seja ele um indivíduo ou uma organização, implica identificar as propriedades (variáveis ou dimensões de variáveis) das classes de estímulo antecedentes efetivamente relevantes para o organismo que se comporta e das classes de estímulos subseqüentes ou conseqüentes a serem necessariamente produzidas por essas respostas, como condição para que a relação comportamental seja aquela de interesse, e das classes de respostas a serem 
apresentadas pelo organismo, para que esses resultados, produtos ou efeitos sejam efetivamente gerados. Na elaboração dessa representação do processo de incubação de empreendimentos solidários, correspondente ao que a equipe da incubadora envolvida neste trabalho considerou, em um determinado momento de sua existência, apropriado aos seus objetivos, cada uma das classes de comportamentos apresentadas no quadro 2 foi descrita em seus componentes.

Quadro 3. Descrição da classe de comportamentos destinados a apoiar a organização inicial do grupo para tomada de decisões a respeito de formação de empreendimento solidário e suas características gerais.

\section{Apoiar a organização inicial do grupo para tomada de decisões a respeito de formação de empreendimento solidário e suas características gerais}

\section{Em que situações ocorre ou deveria ocorrer?}

Grau insuficiente de organização autônoma do grupo e de capacidade para tomar decisões coletivas e democráticas sobre a constituição ou não do empreendimento; grupo informado quanto a temas do cooperativismo, objetivos da INCOOP, bem como sua forma de trabalho e condições, e alternativas para geração de trabalho e renda existentes; interesse do grupo em contar com apoio para tomada de decisões sobre a constituição ou não de empreendimento solidário.

\section{O que a incubadora leva ou deveria levar em consideração?}

Nível de organização do grupo, características socioculturais do grupo, características individuais dos membros, conhecimento disponível sobre moderação de grupos autogestionários, condições concretas para reunião do grupo.

Como a incubadora atua ou deveria atuar para apoiar a organização inicial do grupo para tomada de decisão sobre formação de empreendimento solidário?

A incubadora pode, atuando como facilitadora do processo de tomada de decisões sobre a constituição de um empreendimento solidário e de suas características gerais, garantir espaço físico adequado para que o grupo se reúna, convidar - ou garantir o convite - de todos os que, tendo sido identificados como população potencial, se manifestem como interessados na possível organização de empreendimento solidário; propor procedimentos para discussão das questões envolvidas com as decisões, oferecer informações necessárias para a tomada de decisões ou favorecer a sua disponibilidade para o grupo, apresentar modelos de conduta para análise e processamento de problemas e conflitos no processo de discussão e para argumentação, moderar reuniões e debates, oferecer conseqüências para condutas dos indivíduos que devem tomar as decisões de interesse, favorecer a participação de todos e a tomada de decisões, por meio de processos democráticos e de compreensão da viabilidade. No entanto, essa atuação deve se dar, como em todos os momentos de atuação junto ao grupo, de modo a promover a autonomia do grupo, como, por exemplo, incluindo pessoas do grupo na proposição e implementação das providências, e explicitando, em todas as oportunidades e de todas as formas possíveis, as razões para fazer cada uma das atividades propostas e a função de cada providência ou procedimento sugerido.

\section{O que é esperado, como resultado dessa ação da incubadora?}

Que sejam tomadas decisões sobre formação ou não de empreendimento solidário e forma preferencial de organização, de forma democrática, com participação de todos, e de modo mais harmonioso e compatível com as informações disponíveis sobre as questões em relação às quais as decisões são tomadas, e com autonomia crescente do grupo na condução desses processos de decisão. 
No quadro 3, pode ser vista a descrição de uma dessas classes de comportamentos. Nesse quadro, as duas perguntas, destacadas em negrito, são condições diante das quais foram explicitadas (ou conferidas, em situações coletivas de conferência de versões elaboradas pela pesquisadora) as classes de estímulos antecedentes (sinalizadoras da necessidade, oportunidade ou conveniência de apresentação das classes de respostas sob exame - primeira pergunta - e das condições com as quais a incubadora deverá entrar em contato ou levar em consideração para apresentar a classe de respostas considerada - segunda pergunta). As respostas evidenciam as especificidades desses estímulos, que são consideradas relevantes para a relação comportamental. Da mesma forma, a terceira pergunta se refere a características relevantes da própria classe de respostas sob exame, definidas em função tanto de resultados anteriores da atuação da incubadora nesse tipo de situação quanto de conhecimento disponível indicativo desse tipo de característica da classe de respostas ou, como é usualmente denominado, o "como fazer". Considerando ser a atividade de incubação de empreendimentos solidários uma atividade humana recente, para lidar com uma realidade histórica e social particular e, provavelmente, tão transitória quanto a necessidade que a gerou, identificar e descrever esse processo, em termos de classes de comportamentos, corresponde a reconhecer que os resultados pretendidos em relação aos empreendimentos autogestionários só podem ser construídos pelo fazer humano, individual e coletivo. Fazê-lo justifica-se, entre outras coisas, pelo potencial que esse tipo de análise comportamental oferece para a percepção de quem se comporta - ou deve se comportar - para produzir os resultados pretendidos, sobre a determinação probabilística dos fenômenos, os comportamentos entre eles e a relevância de variáveis componentes de estímulos ambientais e do agir humano, mesmo que sutis, para as características finais que esses fenômenos apresentam ou deixam de apresentar.

Em dois estudos diferentes, Cortegoso e Botomé (2001 e 2002) examinaram propriedades de comportamentos de agentes educativos (supervisores de estudo e recreacionista), em termos das propriedades de diferentes comportamentos (por exemplo, latência, freqüência, duração da resposta de olhar para a criança ou dar instruções) bem como das condições em que se apresentavam esses comportamentos, para os resultados que geravam ou poderiam gerar em termos de aprendizagens dos educandos. Com base em informações sobre esse tipo de propriedade das classes de comportamentos identificadas, foi possível tanto compreender quanto lidar, do ponto de vista administrativo e pedagógico, com situações de ensino, de forma a aumentar a probabilidade de ocorrência de aprendizagem eficaz por parte de usuários da agência educacional em que os estudos foram realizados.

A descrição de comportamentos, em termos de relações comportamentais, torna claros os objetivos a serem atingidos, tanto para a avaliação da atuação da agência em relação a esses objetivos quanto para orientar a ação futura dos indivíduos cujos comportamentos compõem a agência, não por meio da prescrição de respostas automáticas ou padronizadas, mas pela construção de relações potencialmente relevantes e pela utilização tanto do conhecimento quanto da criatividade existentes.

A construção coletiva desse tipo de referencial, como no caso da incubadora a que se referem as classes de comportamentos indicadas no quadro 2, apresenta ainda a vantagem de gerar acordos mínimos para a atuação harmônica de grupos de pessoas que, com histórias de vida diferentes, podem apresentar, e freqüentemente apresentam, maneiras diferentes de compreender fatos e 
acontecimentos, como é o caso de equipes constituídas de professores, técnicos e estudantes de graduação e pós-graduação com diferentes formações e origens. O nível de especificidade envolvido com a descrição de relações comportamentais como a ilustrada favorece, nesse sentido, um debate efetivo, que muito freqüentemente, conforme argumenta Botomé (1994), é escamoteado pelo uso de termos e expressões gerais, que oferecem uma falsa impressão de concordância, somente identificada a partir dos resultados já instalados de ações não apenas diferentes, mas divergentes e desencontradas. É um debate que, de modo coerente com o que propõe a economia solidária, deve permitir a participação igualitária de todos os envolvidos e a comunicação de boa qualidade como condição para a melhoria das relações entre as pessoas, e destas com seu meio.

\section{O que esperar de outros} atores de economia solidária para alcançar os objetivos dessa forma de organização para o trabalho?

Tanto quanto o exame da prática de agências que assumem o papel de incubar empreendimentos solidários, e particularmente para aquelas que consideram como centralidade de sua ação o processo educativo (no mínimo para a autogestão, para a atividade produtiva e para a economia solidária, tal como indicado em Cortegoso et al., 2005a), são essenciais a identificação e a descrição dos comportamentos de outros indivíduos e organizações que contribuem para a existência (ou não) de características (desejáveis ou não) da economia solidária, os próprios empreendimentos econômicos (nascidos ou consolidados a partir de assessoramento externo ou não) e os indivíduos que fazem parte desses empreendimentos, bem como aqueles que são responsáveis pela atuação de agências como as incubadoras.
Acerca daquilo que é ou pode ser esperado de empreendimentos econômicos solidários, atores principais da economia solidária, foram identificadas, por meio deste estudo, classes gerais e específicas de comportamentos, tanto de empreendimentos solidários (como entidades funcionais) quanto de membros desses empreendimentos, potencialmente relevantes para os resultados pretendidos no âmbito da economia solidária. No quadro 4, podem ser vistas as classes gerais de comportamentos propostas, nessa versão preliminar, bem como algumas das classes específicas de comportamentos identificadas para empreendimentos solidários, expressas de forma sintética, ou seja, principalmente por meio da indicação da classe de respostas, sem especificação das condições antecedentes, subseqüentes e das propriedades das classes de respostas relevantes para as relações pretendidas.

São evidenciadas, no quadro 4, as classes de comportamentos gerais que podem ser consideradas relevantes na trajetória de qualquer organização, não apenas dos empreendimentos solidários, servindo essas classes como indicação da importância da dedicação dos participantes do empreendimento a algumas atividades fundamentais e complexas, para que ocorra uma adequada decisão sobre a conveniência e a possibilidade de que o empreendimento venha a existir (propor), que sejam definidas suas finalidades e características essenciais (planejar), que este inicie suas atividades (implantar), seja gerido (implementar) e que seja inserido no contexto mais amplo da economia solidária, de forma consciente e proposital. A especificidade dessas classes de comportamentos, para o contexto da economia solidária, contudo, é dada pela descrição das relações propostas, tal como ilustrada no quadro 5, em relação a duas das classes apresentadas no quadro 4, uma mais geral, e outra, mais específica. 
Quadro 4. Classes de comportamentos, gerais e específicas, propostas como relevantes para empreendimentos solidários no âmbito da economia solidária.

Propor a constituição de um empreendimento solidário que seja viável, relevante e compatível com princípios da economia solidária: identificar necessidades e demandas por serviços ou produtos, caracterizar ofertas de serviços ou produtos disponíveis em relação às necessidades e demandas identificadas, propor trabalho ou produto a ser feito ou oferecido pelo empreendimento solidário, analisar a viabilidade do empreendimento solidário, etc.

Planejar empreendimento solidário em termos de sua finalidade e características gerais: identificar os documentos necessários para constituir empreendimentos solidários, definir o papel do empreendimento solidário na sociedade, definir os objetivos do empreendimento, obter informações sobre os aspectos burocráticos para constituir um empreendimento solidário, etc.

Implantar empreendimento solidário de modo a aumentar sua probabilidade de sucesso: inaugurar empreendimento solidário, encaminhar documentos às instâncias responsáveis;

Implementar empreendimento solidário de forma compatível com os princípíos da economia solidária, no seu funcionamento rotineiro;

Garantir a inserção do empreendimento no contexto mais amplo da economia solidária.

No quadro 5 podem ser vistas as descrições correspondentes a uma classe geral de comportamentos de um empreendimento solidário em formação, que está relacionada à decisão pela proposição (ou não) de um empreendimento solidário em função da existência e do tipo de necessidade social, indicativa de possibilidade de atuação ou desenvolvimento de uma determinada atividade produtiva. Além dessas, são apresentadas as descrições dos recursos disponíveis (mesmo que não estejam imediatamente acessíveis) e de uma das classes específicas que fazem parte da mais geral, relativa à verificação da existência de outros empreendimentos solidários que atuam em relação à mesma necessidade social, de modo a garantir o princípio cooperativista da intercooperação (Rech, 2000). Dessa forma, não devem existir empreendimentos solidários concorrendo em um mesmo segmento de mercado, e um novo empreendimento, caso venha a existir, deve fortalecer a economia solidária por meio de redes de cooperação, principalmente dentro da mesma cadeia produtiva.

Da mesma forma que em relação aos empreendimentos solidários, foi possível identificar comportamentos humanos que, com base na experiência acumulada a partir do acompanhamento de grupos para a formação de empreendimentos solidários, bem como da literatura em economia solidária e em Psicologia, parecem fundamentais como parte do repertório de indivíduos inseridos nesse tipo de empreendimento e na economia solidária. Constituem, tal como os outros tipos de comportamentos evidenciados neste texto (de incubadoras e de empreendimentos solidários), e dentre muitos outros que estão ou necessitam estar articulados para a geração da economia solidária, como resultado de longo prazo de comportamentos mantidos por conseqüências próprias (contingências de reforço), parte da metacontingência de interesse. 
Quadro 5 - Descrição de classes de comportamentos indicadas como relevantes para empreendimentos solidários.

\section{Propor a constituição de um empreendimento solidário}

\section{Diante de...}

- identificação de necessidades sociais sem atendimento satisfatório;

- características do atendimento disponível em relação às necessidades sociais identificadas;

- possibilidades identificadas de atendimento à necessidades sociais;

- potencial humano disponível para atender tais necessidades, por meio de empreendimento coletivo de trabalho;

- recursos disponíveis para atendimento às necessidades identificadas a que o grupo tem ou pode conseguir acesso;

- exigências legais para constituir empreendimentos solidários;

- possibilidades de atendimento de exigências legais.

\section{Resultados, produtos ou efeitos esperados...}

proposta de constituição de empreendimento solidário, compatível com exigências legais, necessidades sociais identificadas, recursos humanos e materiais acessíveis e com princípios da economia solidária, particularmente o de intercooperação.

\section{Verificar a existência de outros empreendimentos solidários que estejam atendendo às necessidades sociais identificadas como possibilidades de atuação do empreendimento.}

\section{Diante de...}

- necessidades sociais identificadas como possíveis frentes em relação às quais podem ser ofertados serviços ou produtos;

- possibilidades identificadas de oferta de serviços / produtos;

- fontes de informações sobre empreendimentos que realizam ou podem realizar atividades em relação à necessidades sociais identificadas na área de atuação do potencial novo empreendimento;

- recursos disponíveis para consultar as fontes de informações sobre outros empreendimentos que podem estar atuando em relação à necessidade identificada.

\section{Resultados, produtos ou efeitos esperados...}

identificada existência ou não de empreendimentos solidários que ofereçam os mesmos produtos / serviços que os identificados como possíveis de serem oferecidos pelo empreendimento em formação.

No quadro 6, podem ser vistas as classes gerais de comportamentos propostas para membros de empreendimentos solidários e algumas das classes mais específicas que as compõem, consideradas objetivos relevantes por pessoas que assessoram empreendimentos solidários para esse trabalho educacional. 
Quadro 6 - Classes de comportamentos gerais e específicas de indivíduos participantes de empreendimentos solidários, propostas como relevantes em função das características da economia solidária.

\section{No âmbito profissional...}

Planejar desenvolvimento do trabalho previsto: conciliar atividades de trabalho e particulares, cumprir compromissos assumidos com o empreendimento; avaliar trabalho em andamento: propor critérios para avaliar o trabalho que está sendo realizado, identificar aspectos positivos e negativos em relação a trabalho que está sendo realizado; promover mudanças necessárias no trabalho: identificar mudanças a serem feitas; tomar decisóes individualmente; investir na própria formação nos vários níveis necessários; engajar-se em atividades de aquisição de novos conhecimentos; capacitar-se para usar equipamentos e recursos necessários para o trabalho.

\section{No âmbito administrativo...}

Participar da administração do empreendimento: manter-se atualizado sobre o funcionamento do empreendimento, participar de eleições para cargos e funções no empreendimento, participar de situações de tomada de decisão no empreendimento; lidar com as dificuldades que o sistema capitalista mais amplo impõe ao empreendimento.

\section{Quanto à comunicação...}

Promover comunicação entre cooperante: produzir veículos de comunicação entre cooperantes (murais, jornais, etc.); estimular o cooperante a expressar para outros a sua idéia/opinião; identificar maneiras adequadas de estimular o cooperante a expressar sua idéia/opinião; comunicar-se com outros cooperados: comunicar-se com outro cooperante da forma mais direta possível, expressar-se adequadamente; identificar características do interlocutor, adequar os comportamentos às características do interlocutor;

\section{Quanto à motivação para o trabalho...}

Promover motivação para o trabalho: motivar a si mesmo e aos outros para trabalhar no empreendimento, enfrentar situações de frustração, identificar causas de erros e fracassos, identificar alternativas;

\section{Quanto ao trabalho em equipe...}

Trabalhar de modo a considerar as necessidades da coletividade; contribuir para o trabalho em equipe; tomar decisões em conjunto; criar oportunidades e condições para que todos os membros do grupo participem dos diversos processos; conviver com as diferenças (religiosas, raciais, socioculturais, etc. ) entre os participantes.

Foram identificados, assim, comportamentos de indivíduos, na esfera administrativa dos empreendimentos, relativos às atividades profissionais a serem desenvolvidas no âmbito do empreendimento, bem como habilidades gerais e específicas de comunicação, de trabalho em equipe e de motivação para o trabalho. Esses comportamentos estão, no quadro 6, apenas indicados por meio de expressões que enfatizam a classe de respostas em questão, e, eventualmente, os aspectos das condições antecedentes ou subseqüentes que se destaquem na relação, estando duas dessas classes descritas, de forma mais completa, no quadro 7. 
Quadro 7 - Descrições de classes de comportamentos de membros de empreendimentos solidários, indicadas como desejáveis em função de características da economia solidária.

\section{Diante de...}

Oportunidades de atuação no âmbito do empreendimento solidário;

- Expectativas da coletividade;

Expectativas individuais;

- Condições disponíveis para revisar expectativas, como compreensão e compartilhamento dos ideais cooperativistas, satisfação com o grupo, etc;

- Objetivos a serem atendidos com a revisão.

\section{Rever expectativas individuais em função das expectativas coletivas}

Com os seguintes resultados, efeitos ou produtos...

- clareza quanto à possibilidade de satisfação das expectativas individuais dentro das possibilidades criadas pelas expectativas da coletividade;

- reavaliação do grau de satisfação individual com o empreendimento como fonte de trabalho e renda e como convivência social.

\section{Diante de...}

- Necessidade de comunicação entre membros do empreendimento;

- Características dos membros do empreendimento (escolaridade, temperamentos, disponibilidade, etc.);

- Objetivos a serem atingidos com a comunicação;

- Recursos (materiais, humanos e financeiros) disponíveis.

\section{Promover comunicação entre membros do empreendimento}

\section{Resultados, produtos ou efeitos esperados...}

- comunicação feita com rapidez, eficiência e economia entre todos os membros do empreendimento;

- acesso de todos os membros do empreendimento às informações de interesse;

- aumento da probabilidade de entendimento entre os membros do empreendimento.

No caso das classes de comportamentos de empreendimentos solidários e de indivíduos que fazem parte desses empreendimentos, e de forma coerente com princípios de economia solidária, como autogestão e participação democrática, esse processo de identificação e descrição de relações comportamentais que representem, da melhor forma possível, aquilo que constitui acordo coletivo sobre o que é relevante, como parte dos fazeres que constituem os elos articulados da metacontingência, cujo resultado é a economia solidária, deverá envolver não apenas aqueles que respondem pelo processo de assessoria a empreendimentos solidários, mas também, e talvez principalmente, os participantes desses empreendimentos. Esses são os protagonistas centrais desse processo e os principais beneficiados, ao menos de imediato, pelo avanço da economia solidária como forma alternativa de organização para o trabalho. Da mesma forma, também a 
participação desses indivíduos na construção de referenciais para a atuação de agências e agentes de fomento a esses empreendimentos (como no caso de incubadoras universitárias) é altamente desejável, de modo que sejam ampliadas a compreensão e a influência mútua de todos os atores sociais que podem contribuir para que os resultados de longo prazo sejam alcançados com a maior brevidade possível.Tais resultados visam não só à obtenção de uma economia solidária forte, consolidada, com novas práticas de organização para o trabalho, mas também a outras práticas de relações entre pessoas, e destas com seu ambiente, diferentes daquelas produzidas pelo modo capitalista de organização social, que são implementadas. No entanto, a explicitação de concepções daqueles que estão trabalhando, a partir de uma incubadora universitária de cooperativas populares, para o fomento desses empreendimentos, constitui, no mínimo, ponto de partida relevante para a socialização dessas concepções, conferência e ajuste de conceitos no âmbito da coletividade que, conjuntamente, deverá garantir os resultados finais esperados e a derivação de propostas práticas de ação.

Nesse sentido, um outro tipo de ator social, em relação ao qual foram identificadas classes de comportamentos desejáveis, é o consumidor de produtos e serviços que, por meio de suas escolhas, pode atuar como favorecedor ou desfavorecedor da existência, das características e da viabilidade da economia solidária. No quadro 8, pode ser vista uma descrição do comportamento consumir, a partir de dados coletados em situações de trabalho coletivo de um grupo que articula consumidores, produtores e distribuidores em favor de um consumo ético, responsável e solidário no processo de definição de seus objetivos.

Quadro 8. Descrição do comportamento consumir, proposto a partir dos objetivos formulados por um grupo organizado, para a promoção de consumo ético, responsável e solidário.

\section{Diante de...}

- necessidades efetivas de consumo;

- diferentes tipos de produtos disponíveis para consumo em relação ao potencial de geração de resíduos;

- produtos gerados com diferentes graus de aproveitamento de resíduos no processo de produção e de respeito ao homem;

- características dos produtores ou prestadores de serviços, quanto à condição social, tipo de organização para o trabalho e benefícios para os indivíduos envolvidos;

- recursos disponíveis para a obtenção dos produtos;

- conhecimento existente sobre as possibilidades de aproveitamento de resíduos e de redução na produção de resíduos.

\section{Prover necessidades próprias, familiares ou de grupos}

\section{Resultados, produtos ou efeitos esperados...}

- necessidades de consumo satisfeitas;

- benefícios para segmentos excluídos, preferencialmente os organizados para geração de renda;

- menor gasto possível de recursos próprios e ambientais;

- ausência de resíduos ou mínimo de resíduos gerados pelo consumo;

- resíduos inevitáveis produzidos com maior potencial de aproveitamento;

- uso máximo de produtos gerados a partir do aproveitamento de outros. 
A descrição de comportamentos humanos ou organizacionais como relações entre o que faz um organismo e o ambiente em que a ação ocorre corresponde a uma estratégia, entre outras possíveis, para a operacionalização de princípios que constituem referencial para todos os indivíduos e organizações que se

comprometem com a economia solidária.
A descrição da classe geral do comportamento de consumidores que aparece no quadro 8 coloca em evidência um conjunto de aspectos a que esses indivíduos necessitam estar atentos, que vão desde a existência de necessidades efetivas até critérios para a escolha de bens e serviços que se referem à qualidade dos processos produtivos, em relação ao ambiente às pessoas que deles participam, à destinação de resíduos oriundos do consumo desses bens e serviços por esse consumidor e ao conhecimento disponível sobre todos esses aspectos. São indicados, ainda, os fatores do ambiente que, decorrentes da ação de consumir e como efeitos de longo prazo dessa ação, caracterizam esse consumo como ético, responsável e solidário, podendo ser esperado que tais resultados, produtos e efeitos venham a influir na probabilidade de manutenção desse comportamento no futuro, de modo, inclusive, a superar o valor das conseqüências imediatas do consumir. Deve-se considerar, especialmente, com muita freqüência, que tais conseqüências imediatas apenas possam manter comportamentos que são, a longo prazo, danosos para a própria vida, o que é muito evidente como resultado de padrões de consumo estimulados pela sociedade de natureza capitalista.

A descrição de comportamentos humanos ou organizacionais como relações entre o que faz um organismo e o ambiente em que a ação ocorre corresponde a uma estratégia, entre outras possíveis, para a operacionalização de princípios que constituem referencial para todos os indivíduos e organizações que se comprometem com a economia solidária. Essa estratégia apresenta, como benefícios importantes, a possibilidade de construção coletiva, a objetividade que torna possível avaliar os impactos efetivamente alcançados com a apresentação dessas classes de comportamentos para os resultados pretendidos e, talvez fundamentalmente, avaliar a crescente visibilidade sobre o papel do fazer humano, individual e coletivo, para a produção das mudanças necessárias destinadas à construção de uma sociedade mais justa e equilibrada, e compreender que essa sociedade que se deseja mudar, por não atender às necessidades, mesmo básicas, de grande parte da humanidade é, também ela, resultado de condutas humanas de muitas gerações, mantidas por nossa própria conduta ao decidir que conhecimento produzir e a quem torná-lo acessível.

As descrições de classes de comportamentos de alguns dos tipos de atores da economia solidária aqui apresentadas têm representado avanço considerável na compreensão do papel de cada um desses atores, ao menos no âmbito de uma equipe de trabalho que atua em uma incubadora universitária de empreendimentos solidários. O processo de construção dessas descrições, baseado na obtenção de informações, tornadas disponíveis em diferentes tipos de situações que fazem parte da rotina do grupo e outras eventualmente coletadas em situações especiais, na sua sistematização e no exame, pelo grupo, dos produtos dessas sistematizações, tem permitido tornar públicas concepções e perspectivas diversas, por vezes contraditórias, em outras, complementares, em relação ao trabalho coletivo. Tem possibilitado, ainda, um crescente reconhecimento de que a economia solidária é e será um produto daquilo que indivíduos e organizações forem capazes de produzir, por meio de sua interação com o contexto mais próximo e mais abrangente. A identificação e a descrição de classes de comportamentos próprias dos diferentes atores que participam de um fenômeno social como a economia solidária, tendo como referencial a noção de comportamento como relação dinâmica do que um organismo faz com o contexto e com os produtos que gera ou são esperados de suas ações, têm se mostrado uma ferramenta relevante para a compreensão e o avanço desse processo, particularmente pela natureza dinâmica dessa representação. Evidentemente, a compreensão e o avanço desse campo não dependem apenas desse tipo de conhecimento, e sua complexidade e relevância justificam esforços múltiplos, de muitas áreas de conhecimento e pesquisadores, de muitos campos de atuação profissional e de profissionais, e, de forma coerente com a economia solidária, de muitos pontos de vista práticos e teóricos. 
ANDERY, M. A. P. A. Uma Tentativa de (Re)Construção do Mundo: a Ciência do Comportamento como Ferramenta de Intervenção. Tese de Doutorado em Psicologia Social. Pontifícia Universidade Católica de São Paulo, São Paulo, 1990.

BOTOMÉ, S.P. Objetivos de Ensino, Necessidades Sociais e Tecnologia Educacional. Tese de Doutorado em Psicologia Experimental. Instituto de Psicologia da Universidade de São Paulo, São Paulo, 1981.

Contemporaneidade, Ciência, Educação e... Verbalismo! Erechim, RS: Universidade Regional Integrada do Alto Uruguai e das Missões, 1994.

Pesquisa Alienada e Ensino Alienante - o Equívoco da Extensão Universitária. Petrópolis, RJ: Editora Vozes; São Carlos, SP: Editora da Universidade Federal de São Carlos; Caxias do Sul, RS: Editora da Universidade de Caxias do Sul, 1996.

BRASIL. Atlas da Economia Solidária no Brasil - 2005. Brasília: MTE, SENAES, 2006.

CONSUMOSOL. Objetivos do grupo ConsumoSol - articulação ética e solidária para um consumo responsável, 2005. Extraído em 21 fev. 2006 de http://geocities.yahoo.com.br/consumosol.

CORTEGOSO, A. L.; BOTOMÉ, SP Relações Comportamentais ao Ensinar em Situações de Recreação Dirigida. Psicologia da Educação, São Paulo, no 13, 2osem., pp. 71-99, 2001.

CORTEGOSO, A. L.; BOTOMÉ, S. P. Comportamentos de Agentes Educativos como Parte de Contingências de Ensino de Comportamentos de Estudar. Revista Psicologia: Ciência e Profissão, v. 22, no 1, pp. 50-65, 2002.

CORTEGOSO, A. L.; SHIMBO, I. Empreendimentos Solidários, Universidades, Movimentos Sociais e Gestores Públicos: Articulação de Esforços na Promoção da Economia Solidária no Brasil de Hoje. Trabalho apresentado na 2 J Jornada Universitaria sobre Cooperativismo, Economía Solidaria y Procesos Asociativos, Montevidéo, Uruguai, 2005

CORTEGOSO, A. L.; SHIMBO, I.; ZANIN, M.; FONTES, D. A.; FONTES N.; IESUS, V. M. B. de; UEHARA, M. S.; MASCIO, C. C.; COSTA, A. A. V. da; NARDINI, T. Método de Incubação como Referencial para Atendimento a Empreendimentos Solidários: a Experiência da Incubadora Regional de Cooperativas Populares da UFSCar. Trabalho apresentado na $2^{\mathrm{a}}$ Jornada Universitaria sobre Cooperativismo, Economía Solidaria y Procesos Asociativos, Montevidéo, Uruguai, 2005a.
CORTEGOSO, A. L.; SHIMBO, I.; ZANIN, M.; FONTES, D. A.; MASCIO, C. C.; CHERFEM, C. O. Variáveis que Influem no Processo de Incubação de Empreendimentos Solidários: um Exame de três Experiências com Base no Método de Incubação da INCOOP/ UFSCar. Trabalho apresentado na $2^{\mathrm{a}}$ Jornada Universitaria sobre Cooperativismo, Economía Solidaria y Procesos Asociativos, Montevidéo, Uruguai, 2005b.

FÓRUM BRASILEIRODE ECONOMIASOLIDÁRIA(FBES). Plataforma de Ações. Brasília, 2005. Retirado em 15 out. 2005 de www.fbes.org.br.

GLENN, S. S. EMALLOT, M. E. Complexidade e Seleção: Implicações para a Mudança Organizacional. In: Todorov, J.C.; Martone, R. C.; Moreira, M.B. (org.) Metacontingências, Comportamento, Cultura e Sociedade. Santo André, S. P.: ESETEc, 2004, pp. 101-119.

GLENN, S. S. Contingencies and Metacontingencies: Relations among Behavioral, Cultural and Biological Evolution. In: Lamal, P.A. (org.). Behavioral Analysis of Societies and Cultural Practices. New York, NY: Hemisphere, 1991, pp. 39-73.

OVERSTREET, H. A. A Maturidade Mental. Trad. Otto Schmeider. São Paulo: Ed. Nacional, 1978.

RECH, D. Cooperativas: uma Alternativa de Organização Popular. Rio de Janeiro: DP\&A, 2000

SECRETARIA NACIONAL DE ECONOMIA SOLIDÁRIA (SENAES). Termo de Referência para o Mapeamento da Economia Solidária e Sistema Nacional de Informações em Economia Solidária. Brasília, 2004

SINGER, P. Economia Solidária: um Modo de Produção e Distribuição. In: Singer, P.; Souza, A.R. (orgs.). A Economia Solidária no Brasil. São Paulo: Contexto, 2000, pp. 11-28.

. Introdução à Economia Solidária. São Paulo:Editora Perseu Abramo, 2002.

SKINNER, B. F. Walden Two. São Paulo: EPU, 1978. 